\title{
POWER THROUGH LINGUISTIC MODALITIES IN INDONESIAN PRESIDENTIAL SPEECHES
}

\author{
Rosyida Ekawati
}

\begin{abstract}
Language plays a crucial role in political speech. The use of a particular language can reflect or be influenced by the speaker's ideology, power, cultural/social background, region, or social status. This paper is concerned with the relationship between language and power, specifically as manifested in the language used by an Indonesian president in international forums. It aims to uncover the power relations that were projected through the linguistic features of the president's speech texts, particularly the use of modal verbs. Data for this paper are the speeches on the topics of peace and climate change delivered by Susilo Bambang Yudhoyono (SBY) in international forums during his first and second presidential terms. This paper's analysis of linguistic modalities uses Fairclough's three-dimensional model of critical discourse analysis (CDA) to answer its research questions. The results show that, in projecting his power, SBY used several linguistic modal verbs. From the context of the modality used it can be understood that the president conveyed his strategic desire to be himself as he tried to relate to the audience (as he assumed it to be) and construct an image of himself, of his audience, and of their relationship. The president produced discourse that embodied assumptions about the social relations between his leadership and the audience and asserted both his legitimate power as president and his expert power. Through the language used, SBY created, sustained, and replicated the fundamental inequalities and asymmetries in the forums he attended.
\end{abstract}

\section{Keywords}

power, modality, CDA, presidential speech, political speech

\section{Introduction}

This paper is concerned with the relationship between language and power, especially as expressed in the language used by an Indonesian president in international forums. Language use plays a crucial role in political speeches, which they influence and reflect. It cannot be denied that language is not always neutral, but can reflect or create power. Although power is an abstract concept, it can be demonstrated and achieved through language use. A study of the language used in political speech, thus, can reveal the power projected by politicians.

Fairclough (1995: 1) emphasises that power is conceptualised both in terms of asymmetries between the participants or groups in discourse events and in terms of the unequal capacity to control how texts are produced, distributed, and consumed in particular socio-cultural contexts. Power is often demonstrated 
through language, and may actually be achieved through language (Thomas \& Wareing 2003: 10, Saville-Troike 2003: 260, Reid \& Ng 1999: 121). For example, political power can be expressed through the language used in political speeches or debates.

In addition, the relationship between language and power is dynamic and multifaceted. It is necessary to examine language in a social context, so it becomes clear that power is not always given, but created, re-created, subverted, and hidden through language. Language can reflect or create power, and the projection of power may depend on the presence or absence of particular linguistic features. Power can be encoded in expressions of modality, either in modal auxiliaries such as may, shall, and must, or in adverbials such as certainly, unfortunately, and obviously.

Through an analysis of the linguistic modalities of political speeches delivered by the former Indonesian president Susilo Bambang Yudhoyono (henceforth SBY) in the international arena, this paper will highlight the relations of power and language. During his two terms as president (2004-2014), SBY was the representative of the Republic of Indonesia, which was economically categorised as a developing country. Recognising this economically less powerful context, I will carry out an analysis of modality - modal verbs, in this context - that may reveal the power relations as expressed in SBY's speeches. This analysis is deemed significant, as it attempts to bridge linguistic and social theory, linking considerations of language use, attitudes, and beliefs with considerations of power.

\section{Background}

Language has a significant role in human communication. People communicate with each other using a mesmerising set of languages which differ in countless ways. The way people perceive language is the foundation of their social constructions and their individual/group relationships. Here, language is viewed as an instrument for consolidating and manipulating concepts and relationships in the area of power and control (Fowler 1985: 61). As such, the spoken or written use of a particular language can stem from different sources, such as ideology, power, cultural/social background, region, or social status.

In political speeches, the process of verbalising thoughts and transmitting ideas does not simply involve pure and unbiased statements (Sornig 1989: 95). It involves the simultaneous signalling of purposes, aims, and wishes, along with the message itself. From that it is obvious that some features of the utterances in the actual speech event are focused on the elements surrounding 
them. Understanding the co- and contextual environment is thus crucial for understanding such linguistic expressions.

Presidential speeches are good examples of political speech, containing within them power struggles. During his two terms, Indonesia's sixth (and first directly elected) president, Susilo Bambang Yudhoyono regularly attended and played an active role in regional or international forums, both in Indonesia and abroad. In those forums, SBY was acknowledged through numerous awards. From this it can be assumed that, through his achievements in the international arena, SBY gained a good reputation. This can offer a good opportunity to examine how he exercised his power in producing his speeches.

In addition, Chilton (2006: 3 ) proposes that politics is viewed as a struggle for power. From a linguistic point of view, one key factor that determines political figures' success in achieving their goals and winning public support in this continuous power struggle is their ability to persuade and influence their audiences through their speeches. Through language use, politicians create, sustain, and replicate the fundamental inequalities and asymmetries in society (Saville-Troike 2003: 254).

One approach used by politicians in projecting power is the use of linguistic modalities. In general, modality refers to speakers' attitudes towards or opinion about the truth of the propositions they express. It also extends to speakers' attitudes towards the situations or events they describe. Moreover, modality is related to the way in which speakers and writers use language to comment on or express attitudes and beliefs and to assert their own points of view. It is an explicit comment which signals the varying degrees of certainty speakers have about what they say or write, as well as the sort or degree of commitment and obligation they express.

Clark (2007: 151) states that modality, grammatically, is most commonly realised through modal auxiliary verbs. Nuyts (2006: 2-6) identifies three categories of modality: dynamic, deontic, and epistemic. Dynamic modality is characterised as an ascription of capacity to the subject-participant of the clause. This category is not restricted to ability alone, but also covers the indication of a need or necessity for the first-argument participant. As such, it covers not only the capacities/abilities/potentials and needs/necessities that are fully inherent to the first-argument participant, but also covers abilities/potentials and needs/ necessities that are determined by local circumstances. Dynamic modality, thus, may possibly need to be extended even further to cover cases that go beyond the abilities/potentials or needs/necessities of any participant in the state of affairs, thereby characterising a potential or a necessity/inevitability inherent in the situation described in the clause as a whole. 
Deontic modality is defined in terms of permission and obligation. In more general terms, however, it may be defined as an indication of the degree of moral desirability of the state of affairs expressed in the utterance, typically, but not necessarily, on behalf of the speaker. Expressions of permission, obligation and interdiction can be considered more complex, as they not only involve an assessment of the degree of moral acceptability of a state of affairs, but also a translation of this assessment into (non-verbal) action terms.

Meanwhile, epistemic modality concerns an indication of the estimation typically, but not necessarily, by the speaker - of the chances that the state of affairs expressed in the clause applies in the world. In other words, it expresses the degree of probability of the state of affairs, as indicated by the modal auxiliary will or the modal adverb maybe. Epistemic modality expresses the degree of the speaker's attitude towards the truth of the proposition.

In addition, the meanings of modal verbs comprise strong and weak modalities, reflecting the speaker's degree of commitment to the truth value of a statement. The higher the degree of commitment, the stronger the meaning of the modal verbs. Conversely, the lower the degree of the commitment to the truth value of a statement, the weaker the meanings of the modal verbs.

\section{Method}

This paper investigates the Indonesian presidential speeches on peace and climate change delivered at international forums attended by the leaders of various nations. It aims to uncover the power relations that he expressed through the linguistic features of five speech texts. This study is descriptive-interpretative within the framework of discourse analysis.

The data were obtained through the internet, from the official presidential website (www.presidenri.go.id) and the website of the Permanent Mission of the Republic of Indonesia to the United Nations in New York (www.indonesiamissionny.org). These data consisted of speeches delivered at international forums, i.e. United Nations Summit and General Assembly, G-20 Leader Summit, and Global Summit, with the topics of peace and climate change (environment). The data that are analysed are therefore derived not from the actual spoken speeches but the written text of the speeches.

From the speech texts, the use of modal verbs representing the projections of power was classified. The modal verbs used were coded following the formation of source text (codeS), data number (codeD), and reference number (codeRef.). Each modal verb used in the texts was not analysed; rather, representatives of each category were analysed, using examples of the modal verbs used in the form of 
words, phrases, and clauses. These English-language modal verbs were analysed using Fairclough's three-dimensional model of critical discourse analysis.

In the description stage, this paper discusses the language (i.e. modal verbs) used by SBY in his speeches, emphasising more the surface meaning of the utterances, while the interpretation and explanation stages discuss the meaning of the utterances from their context and analyse the power the president sought to project. The analysis goes from the micro level to the macro level, from textual analysis to the wider scope of social practice. This has been done to ease the relation of the text and its formal aspects to society. Although analysis goes from the micro to the macro level, it is not unidirectional per se. Rather, it simultaneously examines the data to reach the objective of the study. Using this view, every linguistic modality can be explained precisely from the point of its historical, social, and political context.

\section{Findings and discussion}

Before discussing power in the texts of presidential speeches, it is necessary to remember how power is enacted in discourse. First, power in discourse discusses what the speaker has said or the doer has done; second, the social relations in which people go into discourse discussing what they are doing, and third, the subject positions that can be occupied or refer to who they are. Ruling participants control and limit the contributions of non-powerful participants in these three ways (Fairclough 1989: 46).

\subsection{Modalities used in the speech texts}

The linguistic modalities, modal verbs in this context, used in SBY's presidential speech texts include can, could, have to, may, must, shall, should, will and would. Those modal verbs can be interpreted as the means that the speaker expresses his attitude towards the propositional content of the speech he has made, and as a mode of functioning to regulate interpersonal relationships. The modal verbs used in these speeches are analysed based on the relational values of their grammatical features, as related to their social functions.

\begin{tabular}{|l|c|l|}
\hline Modals & Frequency & Meaning \\
\hline May & 2 & $\begin{array}{l}\text { Possible judgement from his point of view; possible conclusion from } \\
\text { his assessment }\end{array}$ \\
\hline Will & 24 & Prediction, commitment of support, conditional consequences \\
\hline Can & 27 & Ability, encouragement to others \\
\hline
\end{tabular}


Rosyida EKaWATI

\begin{tabular}{|l|c|l|}
\hline Modals & Frequency & Meaning \\
\hline Could & 2 & Potential ability/tentative possibility, impossibility, colloquial \\
\hline Must & 21 & Strong necessity/obligation, confidence \\
\hline Have to & 2 & External obligation \\
\hline Shall & 2 & (= will) \\
\hline Should & 6 & Obligation, desirability, advisability \\
\hline Would & 6 & Volition \\
\hline
\end{tabular}

Table 1: Modalities used in speech texts

In the text of SBY's presidential speeches, modalities are used to express his knowledge, belief, judgement, or assessment of a certain matter or thing. As stated by Coates (1983: 18), modality is concerned with the speaker's assumptions or assessment of possibilities and, in most cases, it indicates the speaker's confidence (or lack thereof) in the truth of the proposition expressed.

SBY rarely used the modal may in his speeches. Of the speech texts analysed, there are only two expressions of the linguistic modal may. Example (1) provides an insight into how the president used the epistemic speculative modal may in the speeches to express a possible conclusion based on his assessment, in particular on the use of recycled materials, planting trees, and using efficient appliances in relation to environmental issues.

(1) We need to have faith on [sic] many approaches that may look trivial and small, such as use of recycled materials, planting trees in your back yard, and using energy efficient appliances. (S1, D3, Ref. 1)

Another expression of the use of epistemic modality appeared in Example (2).

(2) Strategic miscalculations in disputed theatres may lead to rising tension and armed clashes. (S1, D4, Ref. 1)

In Examples (1) and (2), SBY used the modal verb may. May expresses an epistemic possibility, a weak modality. The use of may only gives a judgement that is possible from the speaker's point of view, rather than the only possible conclusion. In this case, SBY did not dare state an ultimate conclusion that must be followed by everybody. From the choice of the modal verb may, it seems he was not exercising his power. May refers only to epistemic possibility, which is a weak modality compared to modal verbs such as must. In both cases, the 
modal verb may was used when the president was not exactly sure in his own assessment of a certain case.

The linguistic modal will, which constitutes an epistemic assumptive modality, was also used in presidential speech. The modal verb will, in the form of negation or in its passive form, is scattered in the texts. Will in the texts has reference to central epistemic, futurity, and conditional consequences (Huddleston \& Pullum 2002).

First, no matter how difficult the challenge before us, let us make history by ensuring that Copenhagen will not fail. (S2, D1, Ref. 1)

In Example (3), will shows us a reasonable belief: Copenhagen will be successful. SBY, in this moment, was expressing his attitude regarding the plan initiated by the Copenhagen forum. The speaker made this statement based on a similar case to oversee such climate change programmes. As such, will presents the idea of his belief in the programme, although it is only his own belief based on prior experience. It is not an attempt to strongly convince the audience to believe that his statement is the only way to ensure the programme's success.

Another example of the modal verb will being used in a presidential speech is as follows.

(4) It is possible that in the end we will have an action plan which will be criticised and scrutinised by the world. Some will say that it is too ambitious and hard to reach, while others will say that it is too little too late. Yet others will also doubt about [sic] compliance and implementation. (S1, D1, Ref. 2)

Four examples of the modal verb will are found in Example (4). Will does not always constitute the future. The use of the modal will also expresses willingness and prediction (Azar 2002: 52). It is understood that the use of the modal will expressed SBY's prediction for the future. Based on his personal lens and beliefs, he predicted what the United Nations (UN) would have in the future and what responses would be received by its policies. Although this utterance was only a prediction, it was made based on SBY's own experiences conducting similar policies. As such, SBY expressed a hope that UN members would conduct themselves a similar matter as he had before. The power of successful experience is expected to positively affect the audience and convince them to undertake such an action for the betterment of the world.

Another prediction for the future conveyed in SBY's speech text is presented below. 
(5) The human race will need plenty of clean air, food, energy, water, and other resources. However, according to some estimates, by 2050 our energy resources will be short by $40 \%$ and food supply by $60 \%$. (S2, D2, Ref. 1)

The use of the modal will in this presidential speech mostly expresses SBY's prediction for the future, specifically in 2050 . He made this statement based on the actual conditions of the population, as related to resources and food. His prediction was not merely an assumption, but a prediction based on data and experience. In using the linguistic modal will for predicting the future, SBY exercised power that was rooted in his experiences conducting programmes such as those being pursued by the UN. He also made an argument based on the existing data. As such, the modal will is also considered to be convincing, despite still being a prediction of the future.

Another use of the modal will is to express willingness, as in the following sentence:

(6) We fully support this initiative and will actively be involved in the process to establish the fund in Durban at the end of this year. (S2, D2, Ref. 4)

The linguistic modal will in Example (6) was used to express his willingness to support the UN's innovative idea for a green economy programme. As UN members, all must have the will to support all programmes, especially those dealing with climate change. In this example, will does not refer to the future, but the willingness of the speaker and the audience.

Another use of the modal will, aside from expressing willingness and making predictions, is to refer to conditional consequences (Huddleston \& Pullum 2002).

Achieving a green economy will require collective vision, creativity, action and support from a broad cross-section of society, especially the business community. It will require sustainable consumption and production as part and parcel of a green economy. (S2, D2, Ref. 8)

The modal will in (7) is used to convey the consequences of the programmes' goals. Both in the first and second sentences, the modal will refers to the consequence of the green economy idea. Achieving this programme's goals requires some conditions be fulfilled. By saying so, the president supported his rational through his own experiences with similar programmes. All of his utterances were based on his previous experiences with the programmes that he had conducted. It was hoped that, by providing examples, the audience easily would readily agree with the proposed idea. 
SBY also used the modal can in his speeches. This modal expresses ability/ possibility, informal permission, informal polite request, or impossibility in the negative form (Azar 2002). In SBY's speeches, the modal can mostly refers to ability.

Many doubt if [sic] we can make a breakthrough. Many do not believe that we can. (S3, D1, Ref. 1)

In Example (8), the modal can indicates the UN's ability to pursue its programmes. Regarding the issue of climate change, SBY believed that the UN would be able to handle it, despite negative comments. The most important thing was to prove that the UN would conduct its programmes well.

There is further evidence that SBY was attempting to convince the audience, especially those members from developing countries, on climate issues. He tried, using the evidence he presented, to gain the attention of the audience and ensure that the UN members would be able to generate productive ways to deal with climate change. Examples (9) and (10) offer other examples of the modal can in his speech texts.

(9) With international support, we are confident that we can reduce emissions by as much as 41 percent. (S3, D1, Ref. 4)

(10) This, I think, is a constructive model of cooperation and can be expanded and emulated by other developing countries. (S3, D1, Ref. 5)

SBY also used the modal can - in negative form - to express ability and thereby encourage others in his speeches, as follows:

(11) We cannot allow any gaps after the expiry of the first commitment period of the Kyoto Protocol in 2012. Remember: "We can negotiate about the climate, but we cannot negotiate with the climate." We cannot ask the climate for more time. (S3, D2, Ref. 1)

The use of the negative form, cannot, in the first sentence of (11) indicates that there is no excuse for UN members to ignore efforts to reduce gas emissions, even after commitments to the Kyoto Protocol expired in 2012. In the second sentence of (11), cannot refers to the impossibility of UN members compromising with the climate. SBY tried to convince the audience that members can only compromise in discourse about the climate, not with the climate itself. He used the prepositions with and about after the verb negotiate when trying to compare the discourse on climate. 
In his speech on climate change, SBY compared the green life policy he made during his leadership of Indonesia with the policy being made by the UN and its members. He provided some examples and evidence to make people believe in his ideas. He tried to explicate all of his efforts concerning how to deal with nature and deal with climate change.

And with the support of the international business community, I believe Indonesia can implement a green economy to achieve 7\% economic growth and $26 \%$ reduction of greenhouse gas emissions from the business as usual scenario by 2020. (S3, D3, Ref. 4)

Another way to convince the audience to create policies corresponding to the climate is by showing the background and support of all members, a point that all members can start with.

You do not have to wait for the multilateral negotiations to produce a new global climate treaty: you can start to act now to make a difference. (S3, D3, Ref. 2)

SBY provided not only examples of policies dealing with climate, but also provided similar models to benefit agendas promoting world peace. He used as an example a similar policy in which he had been involved. The ability to implement peace policy depends on the willingness of UN members, as he exposed the successful deeds of other groups.

And we regard this as the apex of strategic trust, which we believe can be replicated everywhere. As much as we believe that a [sic] culture of peace that ASEAN has practiced can grow in other parts of the world. (S3, D3, Ref. 3)

The use of the dynamic modal can in SBY's presidential speeches mostly focused on belief in the UN and its members' ability or potential to establish policies or otherwise address issues of climate and peace. In reverse, the use of the negative modal cannot in his speeches exposed the impossibility of a certain thing. Successful examples were often used to persuade audiences to follow his ideas and thoughts.

Next is the use of the modal could. Azar (2002: 200) states that the modal could expresses past ability, polite request, suggestion, degree of certainty, and, in its negative form, impossibility. The modal could only appeared twice in SBY's speech texts, once in its positive form and once in its negative form. 
(15) The price of inequality between nations and within nations could be tension born of grievances that can, unless effectively addressed, lead to radicalism and even violence that threaten international and national peace and security. (S4, D1, Ref. 1)

The modal could above expressed SBY's opinion regarding the creation of peace in the world. As such, it expresses tentative possibility in the affirmative context. SBY seemed not entirely sure what caused discord and insecurity in the international community.

Instead of expressing tentative possibility, the negative form of the modal could (could not) expresses impossibility. Could is both the preterit form of the modal can and a separate modal verb.

(16) I could not agree more with the chosen theme of this session "Delivering and Implementing a Transformative Post-2015 Development Agenda". (S4, D2, Ref. 1)

Example (16) provides an insight that the president expressed his certain agreement with the agenda of the event. Similar agendas had been held and were considered a point of his involvement in the issue discussed. The use of the modal could followed by not agree more with is a colloquial expression showing a strong sense of agreement. In the case of SBY, this strong agreement is rooted in his experience holding similar events. The speaker assumed that the agenda of the session was quite in line with the proposed programme discussed in prior forums.

Another modal verb used is must. In its expression, the modal must can be categorised as deontic, epistemic, or dynamic modality. The deontic modal must is commonly used in cases where the speaker is not in a position to - or may not even wish to - require actualisation, such as when giving advice or making requests or exhortations (Collins 2009: 35). In addition, Azar (2002: 199) states that the modal must can be used to express strong necessity, certainty, or, in its negative form, a prohibition.

To exercise power, SBY expressed his idea using the modal must which refers to something that is necessary to do, an obligation for achieving a certain goal.

... we must send the right and positive signals to the world, a signal that climate change remains our top priority even as we wrestle with the financial crisis. (S5, D1, Ref. 1) 
The subjective modal must in (17) provides an exhortation, if not an obligation, for all members of the UN to always prioritise the issue of climate change in all circumstances. He uttered the modal must as a deontic modality, an unspecified consideration of what may be considered morally desirable.

According to Coates (1983: 41) and Huddleston and Pullum (2002: 181), the epistemic modal must implies the speaker's confidence. The speaker is apparently confident that the conclusion presented is the only one possible.

To do all this, there must be mutual accommodation. There must be a forward looking attitude that embraces a win-win predisposition over a zero-sum attitude. Diplomacy must take precedence. Trust deficit must be turned into strategic opportunities and confidence building. (S5, D5, Ref. 1)

In Example (18), SBY indicated confidence in the achievement of a certain thing. He presented and convinced the audience of the best possible way to reach a certain goal. Every occurrence of the epistemic modal must expressed above showed the speaker's confidence in what he believed to be the only solution. He provided some ideas to follow to achieve the ideal desired by all members. The use of the modal must confirmed the speaker's confidence in concluding and providing solutions or ways for addressing certain issues.

Aside from expressing an obligation for the subject 'inclusive $w e$ ', the modal must also works with impersonal subjects. Examples (19) and (20) are examples of obligations or exhortations for impersonal subjects.

Both developed and developing nations must do more and do away with "business as usual" mentality. Developed nations must take the lead, but developing nations must also seriously do their part. (S5, D1, Ref. 4)

(20) Together, the private and the public sectors must collaborate further, and go beyond business as usual. (S5, D3, Ref. 1)

The speaker used the modal must in the above examples, clearly providing insight into the source of his authority. As a member of the organisations sponsoring the forums, he has an equal role and position with other members. To equalise his power, he urged others, i.e. impersonal subjects, to make their best efforts to deal with climate change and world peace. In promoting the realisation of a better world, the speaker considered all nations, organisations, and activities to have the same obligation: to work towards a specific global betterment.

Another example is the modal have to. Although it is not the rival of the modal must in an epistemic sense, the modal have to overlaps with it significantly. The 
situation may change as have to becomes increasingly grammaticalised, with the likely consequence that its epistemic meaning will become more established via the process of subjectification (Collins 2009: 59).

Furthermore, have to focuses on an external, existent obligation that can be perceived or described independently of the speaker, whereas must serves as a very general marker of obligation, with more specific senses such as urgency, irresistibility, and unconditionality being attributable to pragmatic interpretation (Westney 1995: 151).

(21) We have to produce the necessary emission cuts to reach the targets that the scientists say we must. (S6, D1, Ref. 1)

(22) We have to move forward based on the principle of "common but differentiated responsibilities and respective capabilities". (S6, D1, Ref. 2)

Both examples of have to go with subject we, which refers to both the speaker and his audience. The modal have to can express necessity, which differs slightly from the modal must, which expresses a strong necessity. It shows the idea that some actions are necessary to address the issue of climate change. With respect to this expression of modality, both utterances delivered during SBY's speech represented his lexicogrammatical choice and power.

Another English-language modal in SBY's presidential speeches is shall, which is close in meaning to will.

$$
\text { And we shall prevail. (S7, D1, Ref. 1) }
$$

Grammatically, modal shall is commonly used with the subjects $I$ or we. In Example (23), the speaker does not merely indicate a readiness for a certain condition, but also sets an obligation or makes a guarantee to do so with the audience.

This instrument, a product of international consensus, shall serve as a point of reference that the world community must comply with. (S7, D2, Ref. 1)

Example (24) is not a common use of the modal shall. Usually, shall is used constitutively or regulatively when with a third person subject. This is common in legal documents or regulations, but not in examples like the above. This clearly indicates that the modal shall here is equal to the modal will, because shall is rarely used with a third person subject. 
Another grammatical modal used is should. It is basically used to express obligation. In this, it is weaker than must, and stronger than may. Collins (2009: 45) characterised the modal should as an expression of medium strength modality. Meanwhile, Azar (2002: 199) stated that the modal should expresses advisability and certainty for future expectations.

And yet others ask whether we should prioritise climate issues when there is an urgent global financial crisis. (S8, D1, Ref. 1)

Concerning the issue of climate change, the speaker provided the assessment regarding the UN's activities. The modal should expresses the desirability of an action, deriving not from the speaker or from some moral or legal consideration, but from the situation.

... which in their eyes are caused by pollutions generated in industrial countries from decades ago and should therefore be their responsibility. (S8, D1, Ref. 2)

Again, in Example (26), the use of should does not express strong obligation. It is advice for the industrial countries that created pollution as an effect of their activities to take responsibility.

To this end, developed countries must take the lead in our global effort to combat climate change, while developing countries should also engage in much broader actions to go beyond business as usual. (S8, D2, Ref. 1)

The comparison of the modals must and should in Example (27) provides a clear distinction. In the speech, developed countries were identified with must, while developing countries were identified with should. Both types of countries have their own responsibilities, as indicated by the semantic expression of must and should. The strongest obligation in the issue of climate change is borne by developed countries, while developing countries are advised to address this issue in line with developed countries. The speaker tried to formulate the balanced commitment and duty of each type of country to determine an ideal condition.

... we should intensify national efforts and establish partnerships to advance climate security. (S8, D2, Ref. 2)

The modal should lacks the authoritarian implications of must. The modal should in the above example implies a degree of advisability. As such, the use of the negation should not expresses the undesirability of the proposition in the 
speaker's view. The following example gives an idea that the speaker urged that qualified dialogue not be limited to formal discussion, but also include real action.

$$
\begin{aligned}
& \text {...but of course this dialogue should not remain a dialogue, but should translate } \\
& \text { into actual cooperation so that communities in which peoples of different cultures } \\
& \text { and faiths can come together and care for one another. (S8, D4, Ref. 1) }
\end{aligned}
$$

From this discussion of the use of the modal should, it is confirmed that there were no expressions of strong obligation, but rather of advisability.

The last modal expression used in SBY's presidential speeches is would, which expresses polite request, preference, repeated action in the past, unfulfilled wishes, or it politely replaces 'want' when followed by 'like' (Azar 2002: 200). In the past tense, would may express volition (Collins 2009: 140).

It is a plan for sustainable economic growth that would merge Indonesia's commitment to reducing greenhouse gas emissions with clear and actionable steps for achieving strong and sustained economic growth. (S9, D1, Ref. 2)

The modal would in Example (30) expresses volition for the future, in relation to the effort of increasing productivity and reducing gas emissions, respectively.

(31) In such a world, the voice of the moderates - the voice of reason and compassion - would be heard clearly over the din of prejudice and bigotry. (S9, D2, Ref. 1)

And we would have a gentler, better world. (S9, D2, Ref. 2)

Meanwhile, with regards to the issue of world peace, SBY expressed his views on tolerance and compassion. The use of would also revealed the idea of volition. He strongly hoped all nations would apply an extraordinary strategy to create a better condition, as he had experienced in Southeast Asia.

I would say, yes. A resolute yes. For this is what has transpired in Southeast Asia. (S9, D3, Ref. 1)

From the discussion above, it is understood that every single linguistic modality used in presidential speeches has its own purpose and expresses a certain idea that seeks to persuade the audience to agree with or follow its contention. The use of modalities in speech texts could depend on possible judgements from his point of view, or recognise the expressed assessments, predictions, commitments, conditional consequences, abilities, encouragement, potential abilities, tentative 
possibilities, impossibilities, colloquialisms, strong necessities, or obligations, all of which express degrees of confidence, desirability, advisability, and volition.

In his speech texts, SBY tried to expose supremacy, dominance, superiority, authority, and power, particularly that of certain views or beliefs. To be dominant in a social group, a president has the right to manage and benefit of managing what can be said, what should be said, and which perspective is foregrounded in discourse. Through the language used in his speech texts, SBY thus tried not only to guide people's minds and beliefs, but also to control them.

SBY had a chance to exercise his power through the speeches he delivered in international summits on climate change and peace that were attended by the leaders of various nations. He used available power sources to control others, as explicated by the use of linguistic expressions in his speech texts. Coming from Indonesia, which is categorised as a developing country, he often exposed how the country has actively participated in hosting international conferences to anticipate problems that may arise from climate change, from a lack of peace, and from other related actions.

These speeches were delivered in the situational context of international forums, including a United Nations summit, a general assembly, a G-20 leader summit, and a global summit. As such, it is understood that the persons involved in the arena came from countries that were either economically developing or developed. These forums dealt with the ideas of climate change and peace. The Indonesian president, the leader of a developing country, used the chance to articulate his ideas to solve climate change and promote peace. He delivered the speeches in English, which is not his native language, to elicit ideas and present information in an official form.

SBY often used linguistic modalities, in particular modal verbs, in the speeches that he delivered in international forums. The various modals used should be examined separately to establish a network and finally draw general conclusions on their contributions to the text.

\section{a) Others' necessities and obligations}

Obligations in the speech texts are presented through the modal verbs must, should, and have to. It is reasonable that power can be projected through the expression of obligations. The power of command needs to be subjected only to distinctive cases, for example when an agent is hierarchically superior to another. Sources of superiority or power do not attach absolutely to a person, but are relative, granted according to the various resources employed in exercising power. A person or group may more or less control others, or only exert control in a particular situation. 
The use of modal obligations is one indication of power. The holder of power has direct control of the actions that can be achieved through pragmatic discourse that functions as a directive, such as orders, commands, instructions, recommendations, and suggestions (van Dijk 2008: 37). It is thus clear that expressions of necessity and obligation through linguistic modalities support power in the discourse produced by the president.

SBY was able to signal his confidence and oblige others, his audience, to prioritise the agendas of climate and peace. From his speech, it is easy to recall that he used the modal must to express a requirement for all people, particularly audience members. However, this obligation did not only refer to others without involving him, as evidenced by the use of the inclusive we in the subject. It is easy to understand that the power he exercised over others definitely required his participation. His power was not absolute, as he still implicated himself in requiring others to follow his exhortations.

Rather than only involving himself, SBY also expressed obligations for impersonal subjects - organisations, nations, and all attendees. He seemed to have the authority and power to control others and to follow his own ideas. He proposed the best things to accomplish and the best roles to play in bringing changes in the world.

SBY ordered the roles of developed and developing countries. Although he came from a developing country, he had the confidence and courage to reveal this order to all nations. It cannot be denied that, by doing so, he seemed to hold power over the entire audience in the venue, i.e. the leaders of other nations. This included the audience of the Copenhagen conference, held in Denmark in 2009 to lay the framework for the UN framework convention on climate change. From this point, it can also be surmised that, while there was a chance of leaders gathering at this forum, SBY still had a good chance to speak up, as every member had an equal opportunity to express ideas on the topic. Through the use of the modal must, conveying necessity and obligation, it is easy to accept his power and authority in the forum.

Instead of enjoining all members including himself, he advised collaboration between the private and public sectors in achieving certain goals in extraordinary ways. For his rationale, it could be noted that he found a lack of proper collaboration between the different elements of the world. Through collaboration of all elements, he was sure that good team play would ensure better achievements.

In dealing with the issue of world peace, SBY paid more attention to the role of the UN Security Council. As a speaker at the forum, he had the chance to exercise his power over the audience. His equal power in the forum enabled him to equalise himself by uttering a speech that used the modal must to show the necessity of its content. 
Similar to the modal must, the modal have to has similar meanings and functions. Although not many utterances used the modal have to, it also provided SBY a distinguished aspect in terms of power. In his speeches, the modal verb have to also required his own involvement. The personal pronoun we provides insight, as it refers to the speaker and to the entire audience. As such, although he urged others to accomplish his suggestions, he himself participated in all $\mathrm{UN}$ agendas.

From the use of the modals must and have to, it is easy to note that powerful persons commonly have no hesitation when requiring others to do what they suggested. It is a common perception that, to achieve influence over others, a speaker can use expressions of obligation and necessity.

The modal should is another expression of necessity and obligation used in SBY's speeches. Although it has a slightly different meaning and function, should reveals the speaker's strong belief in a matter's necessity. To influence the audience to act in accordance with his beliefs, he needed a convincing reason, which in this claim is related to the power of the speaker. This power stemmed from his knowledge, position, experience, and other related matters supporting his power base.

The use of the modal should implies that the speaker only emphasises the necessity that all organisation members deal with climate change. $\mathrm{He}$ sets a specific reason, namely that - from the view of parties outside the UN members - he and all attendees had an obligation to do as recommended. He set a requirement for others, and to exercise his power over the audience and he confidently stated that developed and developing countries had distinctive roles. He only conveyed his advice that world leaders discuss and address such problems as climate change and world peace.

\section{b) Modalities expressing speaker's belief in ability and capacity}

Related to the issues of climate change and world peace, the speaker supported all members by showing their capacity and capability. He convinced the audience that, as members of world organisations, all nations have made their own efforts to deal with issues of peace and climate change. While recognising that some parties underestimate their abilities and efforts, he still tried to convince the audience to be optimistic and accomplish the actions proposed by the UN.

He confidently said that doubts of other parties could unite members in efforts to prove these doubts unfounded. Others' negative assessments should receive a positive response from organisation members. This indicates that he seemed to force the audience to deal with the negative perceptions and become more active. 
The power enacted in front of the forum was rooted in his experiences as a leader, both in Southeast Asia and in Indonesia. He showed his achievement in dealing with climate and peace issues, both in the scope of Indonesia and ASEAN. Through its exposure, he used his competence to influence others to do what he has done to deal with change and promote world peace.

Belief in the abilities and capabilities of the forum members, as individual leaders, as group members, or as organisation members, led SBY to persuade his audience with his arguments about bettering the world. Using his beliefs, he persuaded his audience to overcome problems through the solutions he offered. By doing so, he exposed his power, derived from the knowledge he had accumulated through his experiences, which could be imitated and implemented on a larger scope.

The use of a colloquial expression, using the modal could in negative form followed by a phrase agree more, can also be an expression of power where the speaker has certain background knowledge of an issue. The reason SBY used such an expression is likely because he had definite knowledge about the agenda. Through his supportive argument, he boldly stood behind the forum's agenda. To invite others to do the same, he exposed his involvement in similar forums. It is thus clear that the power of knowledge can be one key to influencing others.

\section{c) Modalities expressing the speaker's outlook for future}

One of the ways SBY indicated power to the audience in his speech texts is through the use of the medium probability modal will. This modal sometimes indicates that the speaker lacks the confidence to say something directly. The use of the modal will is to avoid the idea of dictating, as if the speaker is asking the audience to agree with his idea. This does not show that the speaker and the audience are equal.

The modal verb will can be categorised as medium probability, as the speaker is not sure what will happen in the future. In the case of SBY, he argued about the probability that the programme initiated by the people attending the Copenhagen forum would be successful. His power was rooted in his previous experiences handling similar agendas.

SBY's expressions of power were based on his own experiences in Indonesia, ASEAN, or internationally, where he handled and faced similar cases of environmental protection and peace building. Relying on his experience, he persuaded the audience by providing examples and reasonable arguments for the struggles people make in realising the ideals of environmental protection and peace. 


\section{d) Modalities expressing the speaker's assessment}

SBY rarely used the modals may and might, which are of epistemic speculative modality. As these modals are weak, they can be expressions of a speaker being less powerful than the audience, such as when offering a personal lens on a certain matter despite having no previous experience (i.e. when a statement seems to come from the speaker's own assessment and seems to be based on the speaker's own assumptions). In this case, these modals are always used when referring to SBY's personal conclusion, which is in-line with Nuyts' statement (2006: 31) that, for epistemic modality, the speaker alone knows the evidence and draws a conclusion from it. In other words, the speaker understands that he is only assuming something without evidences or background experience, and thus that it is less convincing and requires others' approval. Seeking others' approval is an indication that the speaker is less powerful than the audience. The modal may conveys the speaker's own judgement and assessments from his personal lens, without personal success or background knowledge in dealing with the mentioned issues.

Being slightly different from the weak modals may and might, the modals can and could can also explicate a speaker's judgment and assessment of the abilities of a forum members. In this case, SBY used the modal can to expose his belief in people's competence and ability to accomplish all tasks and resolve climate change and promote world peace. His statements were supported by rational and convincing arguments rooted in his experiences and his previous observations. By presenting background, he asked his audience to believe in and continue efforts to realise all proposed ideals and support each other without exception.

\subsection{Power through expressions of modalities}

From the previous section, it can be deduced that the use of modalities could project power. In the international venues where SBY delivered his speeches the audience included members of organisations from different countries, who may have had many differences. To exercise power in front of the audience, he conveyed his ideas about climate change and peace using various modalities.

In his speeches, SBY used modalities to express commands, requests, and announcements. He set obligations for all audience members as well as himself, recognising that he was also a member of the same organisation. He used the inclusive personal pronoun we and the modal verbs must, have to, and should to set requirements for others. Here, the inclusive we included the speaker in doing what had been ordered or suggested. 
The use of the modal verbs must, have to, and should is in line with the findings of Torabiardakani et al. (2015) about the modal verbs used by advanced EFL learners. As a non-native speaker of English, SBY also conveyed his ideas about obligation and necessity using these modal verbs. It can be seen that the obligation meaning of the modal must is more dominant than its necessity meaning, while the expression of necessity is dominant in the modal should.

Through the modalities must, have to, and should in SBY's speeches, in line with van Dijk's (2008) statement about how power is enacted by discourse as a form of social interaction, the president conveyed power, rooted in his knowledge, experience, and background, and was confident in expressing his feelings and asserting his equal status with the organisation members, leaders, and audiences to whom he delivered his speeches and conveyed strong obligations. In such forums, power was not merely held by the leaders of or members from developed countries; all members have the same chances and equal positions in such forums. Conversely, where he lacked the power to order others, he preferred using should to indicate necessity or advisability.

In the speech texts, some statements convey factual data such as statistical numbers. Access to accurate information is also a strategy for showing power. Statements of fact and consequence can also be considered sources of power. Whenever SBY provided facts, he also mentioned some future consequences as potential threats. It can thus be understood that someone who threatens others is one who has power. It is interesting to note that some obligatory expressions were also targeted at the speaker himself, meaning that he also required himself to fulfil the same requirements he set for his audience. All organisation members had equal rights and obligations to achieve the proposed goals, especially the goals of tackling climate change and attaining world peace.

Again, SBY set an obligation for all audience members to try new approaches and apply a strategic mindset when promoting peace and security. He backed his mindset by exposing the role of Indonesia to the UN and its peace and security agenda. In doing so, he used the modal verbs must, should, and have to as orders or commands. This was the way he exercised power, giving his audience directions, suggestions, and advice on resolving conflict. Directives are the most power-dependent and most obvious linguistic realisations of the coercion function (Chilton \& Schäffner 1997: 219). Power might also be expressed using commissives, by making promises or threats. Declaratives also convey power, since only powerful speakers are in the position to make announcements. This power was derived from Indonesia's experiences in handling domestic conflicts as well as regional conflicts in ASEAN. This strategy of positive self-presentation is also a way to express power (Vadai 2016). 
By equalising all audience members using the inclusive personal pronoun we in the speeches he tried to show his power by defining obligations using modulations of obligation. He urged all members to reach their goals, particularly those set in agreements, commitments, action plans, and also consensuses that must be completed by all countries.

SBY had power in groups with the capacity to affirm the general human quest for fulfilment (Veneklasen \& Miller 2002). The speaker's power was expressed through the setting of an obligation for all, namely use of collective strength to ensure better conditions. This obligation is based on the assumption that all people in the same organisation must work together, help each other out, team-up for success, be inter-related, and generally cooperate.

Aside from recognising the role of all countries, SBY also acknowledged the need of expert involvement. By recognising their capacity and expertise - rooted in their education, experience and real thinking - he indicated his power relations with the experts. In the text of his speeches, SBY acknowledged the role and involvement of parliaments, scientists, and environmental activists around the world. This indicated that, in making policy decisions, particularly those related to climate change, he also followed other parties who were considered to have more knowledge, authority, and expertise.

In addition, SBY used modal verbs to express his belief in the audience members' abilities and capacities, mostly based on his own experience. Using his experience and knowledge background, he surely also exercised power over others. It was easier for him to convince and influence others, to have them follow, imitate, and produce fruitful actions for promoting his climate and peace agenda. Following Collins's (2009) statement, ability - in this case - is based on an agent having the potential to perform actions. SBY's beliefs in forum members' abilities were also based on his potential actions.

Another expression of power in the speech texts is evident in the use of the modal will, which is related to the idea of the future time but has been considered and tagged in this study as a subcategory of epistemic prediction. In this regard, the modal will can be considered a confident prediction about the typical behaviour of someone or something (Nordberg 2010). In the context of SBY's power, the modal will was used as an epistemic prediction based on his experiences with similar conditions. Meanwhile, where SBY lacked the confidence to assess or evaluate a situation due to his lack of experience, he preferred only giving his own assumptions, as expressed through the use of the modals may or might. This could show his lack of power compared to other, more experienced, people. 


\section{Conclusions}

Nine kinds of modals were used in the texts of Susilo Bambang Yudhoyono's presidential speeches: may, will, would, should, can, have to, must, could, and shall. Related to the notion of power that the president tried to exercise, each modal verb expresses his power or lack thereof. These expressions of power were derived from various sources of power.

In using modal verbs, SBY often used strong modality. For example, he used the modal must to convince the audience to follow or conduct actions he proposed based on his prior experiences. Similarly, his suggestions and advice were made based on his experience as the president of Indonesia, the chair of UN events, and as a member of Association of Southeast Asian Nations. As such, he used such modality where he had power owing to his real examples and successful experiences. Weak modality, meanwhile, was used when he described and expressed personal opinions or judged things from his personal lens. Nonetheless, he consistently used examples and successful experiences to exercise power and convince audiences.

SBY delivered his speeches confidently whenever he considered himself to have power, such as the legitimacy as Indonesia's president or his experiences and involvement in efforts to realise a better world. Despite coming from a country categorised economically as developing, he readily convinced his audiences. He also acknowledged persons who had expertise he lacked, or used others' experiences and success stories to convince his audiences.

From the above discussion, it may be concluded that, through his speeches, SBY projected his authority to equalise himself and other members of international forums. Implicitly, he sought to project the power relations between Indonesia and other countries through the choice of modalities in his speeches.

\section{References}

Azar, B. S. (2002) Understanding and Using English Grammar. $3^{\text {rd }}$ ed. New York: Longman.

Chilton, P. (2006) Analysing Political Discourse: Theory and Practice. London: Routledge.

Chilton, P. and Schäffner, C. (1997) 'Discourse and politics.' In: van Dijk, T. A. (ed.) Discourse Studies: A Multidisciplinary Introduction. London: SAGE Publications.

Clark, U. (2007) Studying Language. Basingstoke: Palgrave Macmillan.

Coates, J. (1983) The Semantics of the Modal Auxiliaries. London: Croom Helm.

Collins, P. (2009) Modals and Quasi-modals in English. Amsterdam: Rodopi.

Fairclough, N. (1989) Language and Power. London: Longman.

Fairclough, N. (1995) Critical Discourse Analysis. London: Longman. 
Fowler, R. (1985) 'Power.' In: van Dijk, T. A. (ed.) Handbook of Discourse Analysis. Volume 4: Discourse Analysis in Society. London: Academic Press.

Huddleston, R. and Pullum, G. K. (2002) The Cambridge Grammar of the English Language. Cambridge: Cambridge University Press.

Nordberg, T. (2010) Modality as Portrayed in Upper Secondary School Textbooks: A Corpus-based Approach. Unpublished Master Thesis. Helsinki: University of Helsinki. Online document. <https://helda.helsinki.fi/handle/10138/19357>.

Nuyts, J. (2006) 'Modality: Overview and linguistic issues.' In: Frawler, W. (ed.) The Expression of Modality. Berlin: Mouton de Gruyter.

Reid, S. A. and Ng, S. H. (1999) 'Language, power, and intergroup relations.' Journal of Social Issues 55(1), 119-139. DOI: 10.1111/0022-4537.00108.

Saville-Troike, M. (2003) The Ethnography of Communication: An Introduction. Oxford: Blackwell Publishing Ltd.

Sornig, K. (1989) 'Some remarks on linguistic strategies of persuasion.'In: Wodak, R. (ed.) Language, Power and Ideology. Amsterdam: John Benjamins.

Thomas, L. and Wareing, S. (eds) (2003) Language, Society and Power. An Introduction. London and New York: Routledge.

Torabiardakani, N., Laleh K. and Nasrin, S. (2015) 'Modal auxiliaries and their semantic functions used by advanced EFL learners.' Acta Didactica Napocensia 8(2), 51-60.

Vadai, K. (2016) 'Critical discourse analysis in progress: The power, ideology and manipulation identification (PIMI) model.' Alkalmazott Nyelvtudomány. DOI: 10.18460/ANY.2016.1.004.

van Dijk, T. A. (2008) Discourse and Power. New York: Palgrave Macmillan.

Veneklasen, L. and Miller, V. (2002) A New Weave of Power, People and Politics: The Action Guide for Advocacy and Citizen Participation. Oklahoma City: World Neighbors.

Westney, P. (1995) Modals and Periphrastics in English: An Investigation into the Semantic Correspondence between Certain English Modal Verbs and their Periphrastic Equivalents. Tubingen: Max Niemeyer Verlag.

Rosyida Ekawati is a lecturer at the University of Trunojoyo Madura, Indonesia. Her interest is in language and discourse. She published some academic articles dealing with language use in political and public spheres in reputable and accredited journals in Indonesia, such as Humaniora, Journal of Culture, English Language Teaching and Literature (Celt), Bahasa dan Seni, and Lingua. She published some other articles in local journals and proceedings of National or International seminars.

Address: Rosyida Ekawati, English Study Program, Faculty of Social and Cultural Sciences, University of Trunojoyo Madura, Jl. Raya Telang Kamal Bangkalan 69162, Indonesia. [e-mail: rosyida.ekawati@trunojoyo.ac.id] 